\title{
The nutrition transition in Egypt: obesity, undernutrition and the food consumption context
}

\author{
Osman M Galal ${ }^{1,2, *}$ \\ ${ }^{1}$ School of Public Health, University of California, Box 951772, Los Angeles, CA 90095, USA: ${ }^{2}$ High Institute of \\ Public Health, Alexandria University, Alexandria, Egypt
}

\begin{abstract}
Objectives: To describe changing food consumption patterns in Egypt over the last several decades, current levels of overweight and obesity, and current data on obesity-related morbidity.

Design: Secondary analysis and synthesis of existing data from national-level food consumption surveys, large recent surveys of hypertension and diabetes, and documentation of historical and policy context.

Setting: Arab Republic of Egypt.

Subjects: As selected and described in primary data sources.

Results and conclusions: The nutrition transition in Egypt has occurred in the context of abundant dietary energy availability, urbanisation and moderate fat intakes. The prevalence of obesity in adults is very high, particularly among women. The prevalences of diabetes mellitus and of hypertension parallel that of obesity, and both are very high. Little information is available on physical activity, but it is likely that a large proportion of the population is quite sedentary, particularly in the cities. At the same time, rates of early childhood malnutrition remain stubbornly stable and relatively high. Public awareness of the increasing prevalence of obesity and of diet-related chronic disease is increasing, and attention has turned to documenting the problem(s).
\end{abstract}

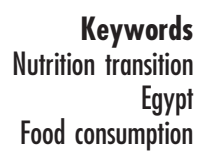

This paper will attempt to describe the current situation in Egypt with regard to the emergence of obesity and dietrelated chronic diseases and their relation to changes in the food supply, food habits and related variables. In addition to the usual food balance sheet and household budget/expenditure surveys, Egypt has very valuable and specific information on food consumption and dietary patterns spanning a considerable time period. Egypt was one of the earliest countries to follow the recommendations of the Health Section of the League of Nations in 1939 and publish a food composition table of local foods in order to undertake dietary surveys. When World War II intervened, it was not until 1959 that sporadic activities resumed. Since then there have been three major national food consumption surveys: (1) one in 1981; (2) a second in 1998 that was essentially a repeat of first; and (3) the third is planned as a continuous monitoring system that began in 1994, with a second round in 1999. Nutritional status surveys at the national level have focused mostly on preschool children. Morbidity data on national samples are relatively recent but provide an overview of current trends in relative body weight for adolescents and adults, and the prevalence of obesity-related morbidities.

\section{Demographic, political and economic background}

Political and socio-economic changes in Egypt since World
War II and resultant changes in lifestyle have taken place in the context of a series of policy initiatives that have affected both the economy and the food supply. Major milestones include:

1. the land reclamation law in 1953 ;

2. the nationalisation of all foreign property in 1956 ;

3. the food subsidy policy implemented in the early 1960s;

4. the 'open-door' economic policy introduced in 1974;

5. the series of laws passed in 1980 designed to encourage temporary immigration of human resources to rich oil-producing countries; and

6. most recently, during the 1990s, the economic restructuring imposed by the International Monetary Fund (IMF) that has largely dismantled consumer subsidies (except for bread) and encouraged privatisation of the economy.

These policy and legal initiatives have resulted in major changes in daily life for most Egyptians and have contributed strongly to changes in dietary patterns - the results of which are now seen in the health profile of the Egyptian population.

Over this period of time, Egypt has undergone relatively rapid population growth, averaging $2.8 \%$ per annum to the present number of approximately 65 million $^{1}$. Food production has not kept pace in spite of major investments 


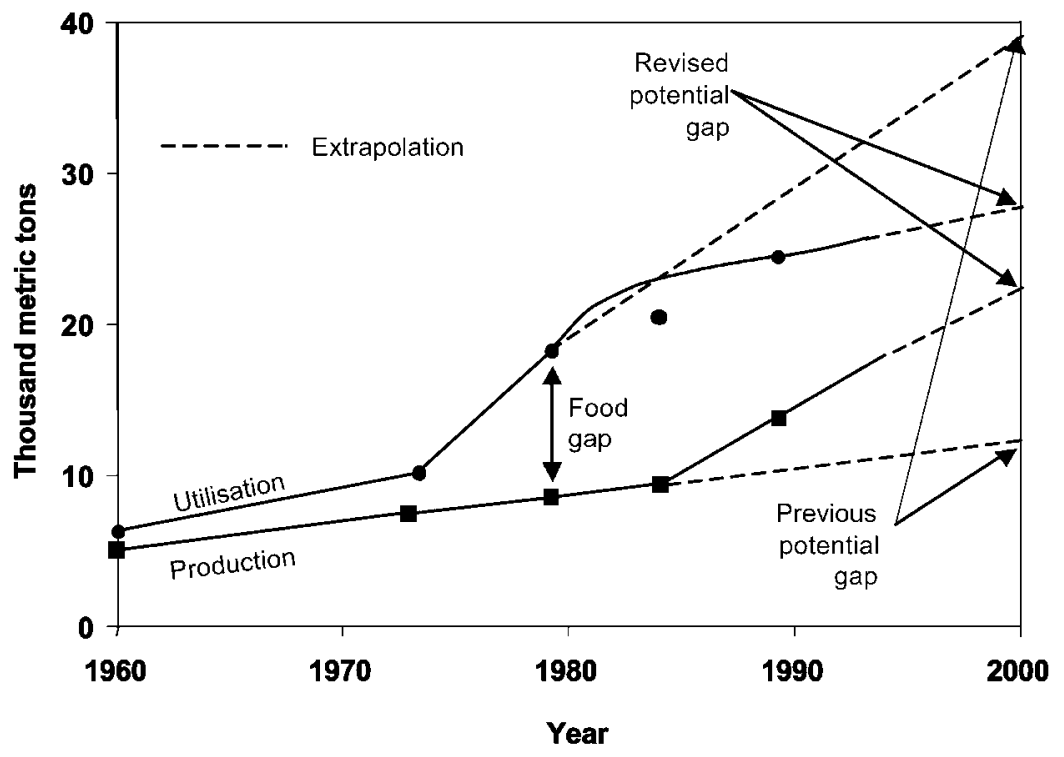

Fig. 1 Domestic food production and utilisation, 1960-1990, with extrapolations to 2000. Source: York et al., 1994 ${ }^{3}$

in agriculture and increases in overall production. In 1960, Egypt was essentially self-sufficient in food ${ }^{2}$. Consumption of the nine main food products (wheat flour, maize, lentils, sugar, cooking oil, red meat, poultry, dairy products and fish) increased dramatically during the 1970s and onwards. By 1980, the gap between agricultural production and food consumption had reached about nine million tons (Fig. 1) ${ }^{3}$ in all food commodities combined ${ }^{4}$. This led to the importation of food, which not only increased availability of food commodities but also introduced new foods into the marketplace that had not previously been part of the traditional cuisine. Some of these (e.g. macaroni, processed cheeses) have since become widely consumed and integrated into the general dietary structure of the country. The heavy economic burden of food imports led to major investments in the agricultural sector beginning in the early 1980s, with the goal of narrowing the gap between food production and consumption. Agricultural production increased sharply, and imports dropped (e.g. imported wheat was at its maximum in 1987 at 7.4 million tons and dropped to about 5.3 millions tons by 1993). The second major attempt to reduce the economic burden associated with ensuring the food supply has involved curtailing the extensive food subsidy system at the consumer level. The process of dismantling consumer subsidies did not really begin until the early 1990s, in response to IMF pressure; bread is the only food commodity heavily subsidised today. As subsidies were removed between 1990 and 1994, food prices increased sharply and at a higher rate than general inflation; for most food commodities, prices increased three- to tenfold during that period while wages less than doubled ${ }^{5}$. The total household food consumption dropped dramatically, by about $20 \%$, during that period.

\section{Early data on food consumption in Egypt}

The earliest dietary studies (conducted between 1939 and 1946) were: (1) two studies in the Nile Delta villages of the diets of individuals in communities afflicted with pellagra, which was endemic in Egypt at that time; and (2) a third study that focused on factory workers in urban Alexandria $^{6}$. The results showed the average energy intake for adults to be upwards of $2500 \mathrm{kcalday}^{-1}$ and protein intakes to be more than adequate by about $100 \mathrm{~g} \mathrm{day}^{-1}$. Corn bread mixed with a little fenugreek (3\%), or with wheat flour $(30 \%)$, was the staple food; lower-income groups consumed fewer dairy products and fruits than higher-income households, and the urban sample had a more varied diet in terms of meat, fish, dairy products and legumes. There were more than 80 studies conducted between 1959 and 1978 that were sufficiently documented to be accessed today; all were done on relatively small samples (usually $<100$ ) and the majority were urban. Results generally showed: (1) adequate energy and protein intakes (except for one study of Bedouins in the Sinai in the mid-1970s) ${ }^{7}$; (2) advantages for urban inhabitants in terms of dietary diversity and quality; and (3) generally low intakes relative to requirements for pregnant and lactating women across a number of samples.

\section{Changes in food availability}

Data from food balance sheets show there were two major shifts in the Egyptian food supply from the mid-1950s to the mid-1990s. One was an increase in per capita grain availability and a shift from a dependence on mixed grains (wheat, corn, rice and sorghum) to a more nearly total 
Table 1 Food commodity availability, late 1950s and 1990s

\begin{tabular}{lcr}
\hline & \multicolumn{2}{c}{ Availability $^{\left(\mathrm{kg} \mathrm{person}^{-1} \text { year }^{-1}\right)}$} \\
\cline { 2 - 3 } Food commodity & $1955-60^{*}$ & 1997 \\
\hline Cereals & 186.0 & 280.0 \\
$\quad$ Wheat & 72.0 & 132.0 \\
Rice & 27.0 & 52.0 \\
Corn & 88.0 & 79.0 \\
Legumes & & \\
Fava beans & 7.7 & 6.1 \\
$\quad$ Lentils & 1.3 & 1.0 \\
Potatoes & 5.0 & 17.1 \\
Vegetables & 63.0 & 119.0 \\
Fruits & 66.0 & 92.0 \\
Refined sugar & 17.5 & 29.0 \\
Fats \& oils & 4.6 & 15.6 \\
Meat/poultry & 7.4 & 16.3 \\
Fish & 4.3 & 9.1 \\
Dairy products & 42.0 & 75.1 \\
\hline
\end{tabular}

*Average $1955-60$ or 1960 data, depending on availability.

dependence on wheat. The other was a sustained rise in the availability of sugars, oils and fats, and meat/poultry/ fish. Legumes have decreased in importance, and fruits and vegetables have remained relatively stable. Table 1 summarises these overall trends in terms of per capita availability. There is evidence of a sharp increase in agricultural production since the mid-1980s. As a result of this increase, coupled with a moderation in the rate of increase in food consumption (due mainly to reduced population growth rate and significant reduction in food subsidies), projections to the year 2000 indicate a potential food gap of only 4.5 million tons - only $17 \%$ of the gap projected in the early 1980s (Fig. 1).

The shift towards dependence on wheat began with major consumer education efforts to decrease the dependence on corn and the resultant risk of pellagra, documented to be an important public health problem in $\mathrm{Egypt}^{8}$ in the 1950s and earlier. Traditionally, the staple Egyptian bread was made of corn mixed with wheat in a roughly $60 / 40$ or $70 / 30$ ratio, or corn alone with a small admixture of fenugreek. Poor rural areas, and in particular the Delta, were endemic pellagra areas. Pellagra has disappeared in Egypt as a result of the shift towards wheat consumption and general improvement in availability of animal products. In the mean time, wheat consumption has increased dramatically, due both to consumer preference and to the availability of inexpensive flour and bread as a result of subsidies. The consumption of rice, long a preferred cereal, has increased but still represents a modest share of the total cereal consumption. Per capita rice consumption has fluctuated over relatively short periods depending on export policies, which in years of heavy exports have suppressed domestic consumption.

Over the same period, food commodities indicative of dietary quality (vegetables, fruits, meats, fish and dairy products) have increased steadily in overall availability. Fat and oil availability (mainly cottonseed oil for cooking and margarine) has more than doubled, and refined sugar use (mostly in tea and soda drinks) has increased substantially.

\section{National food consumption data}

The first organised national food intake survey was accomplished in 1981 by the National Nutrition Institute? The study included 35334 persons in 6300 households from six of Egypt's 24 governorates; the sample size at that time represented $0.1 \%$ of the population. Food frequency information was obtained at the household level and quantitative 24-hour recall of food intake of individuals was collected on a sub-sample of 1260 households. At that time, only $24 \%$ of urban and $15 \%$ of rural households reported consuming ready-made food. As a cultural practice, almost all households reported using one dish (entrée) for serving all persons partaking of a given meal. More than three-quarters of rural households and 38.5\% of urban households reported breeding livestock. There were substantial rural/urban differences in food consumption patterns. Almost all urban households ate wheat bread on a daily basis, while rural households most often reported a wheat/corn mixture in their daily bread; however, two-thirds of these reported eating wheat bread in addition. Meat was more often eaten in urban households (on $25.3 \%$ of days) than by rural families (3.6\% of days).

A repeat National Food Consumption Survey was implemented by the Nutrition Institute in 1998, utilising a sampling procedure similar to and in the same governorates as the 1981 survey $^{10}$. Three hundred households were studied in each district; urban and rural households were represented according to their actual proportion in each governorate, and districts (primary sampling units) were selected randomly within each governorate. Household food frequency and quantitative intake sampling of one child, 2-18 years old, and his/her mother were collected with a total sample of 1669 households with 9134 individuals. Results showed that more than $50 \%$ of the total sample consumed the staple diet of wheat bread, sugar, ghee or butter, vegetable oil, milk and tea daily. Subsidised wheat bread (balady bread) was the most common bread, followed by mixed wheatmaize home-baked bread in rural areas. The majority of households depended on poultry as the main meat/fish/ poultry source, consuming an average of $65.8 \mathrm{gday}^{-1}$; a majority of surveyed households reported raising poultry at home. An average regular consumption of $30.7 \mathrm{~g}$ person $^{-1}$ day $^{-1}$ of eggs was reported. Fresh vegetable and fruit consumption was an average of $51.5 \mathrm{~g} \mathrm{day}^{-1}$ and $101 \mathrm{~g} \mathrm{day}^{-1}$, respectively. Tea and carbonated soft drinks were the most commonly consumed beverages. In terms of nutrient intake, almost all households reported food 
intake levels that met daily requirements for energy and protein. Dietary quality deficiencies were evident for iron, calcium and vitamin A intake, with more than half of households reporting intakes well below recommendations.

Although the average energy intake declined between the 1981 and the 1998 surveys (from $2843 \mathrm{kcal}$ to $2619 \mathrm{kcal})$, the proportion of households consuming $>3500 \mathrm{kcal}_{\text {person }}{ }^{-1} \mathrm{day}^{-1}$ increased from $11.2 \%$ to $17.1 \%$ and the proportion consuming $<1500 \mathrm{kcal}$ person $^{-1}$ day $^{-1}$ decreased from $16.8 \%$ to $7.7 \%$. A comparison of the 1998 and 1981 food consumption survey data shows a major increase in meals eaten away from home (45.8\% of all meals in 1998 vs. 20.4\% in 1981), with away-from-home eating more common in urban than in rural areas. In the Egyptian context, meals eaten away from home not only represent those consumed in restaurants, street foods, work and school site meals but also meals eaten at the homes of relatives, which for many families is a regular proportion of their meals. A patrilocal residence pattern persists, and a great many extendedfamily eating occasions characterise everyday life. A decrease in home bread-making was also striking, with $55.9 \%$ of households reporting consumption of homebaked bread in 1981 compared with only 17.5\% in 1998.

A large food consumption survey in 1994 that was designed to be the baseline of an ongoing food consumption monitoring system was conducted by the Agricultural Research Center ${ }^{11}$. The sample size was over 6000 households, or about $0.11 \%$ of the Egyptian population. The sample was drawn from five of the 24 governorates of Egypt, selected to be representative of different areas: Greater Cairo representing the urban population of the capital city; Dakahlia and Ismailia representing Lower Egypt; Aswan representing Upper Egypt; and New Valley representing the frontier areas. Only the Cairo governorate overlapped with the 1981 and 1998 Nutrition Institute studies. The sample size for each governorate was proportional to the population, at a rate of one per thousand households, but under the stipulation that the minimum sample size would be 10 households month $^{-1}$ in each primary sampling unit. Each of the governorates except Cairo was divided into rural and urban sampling units, and the sample was selected so that urban and rural households would be represented according to their actual proportion of the population in each governorate. The study households were visited in all five governorates throughout an entire year (November 1993 through October 1994) to capture any variation in food intake and nutritional status associated with the agricultural or religious calendars. Household-level food frequency data and individual quantitative 24-hour recall data were collected, the latter only from the adult female survey respondent and one child, aged 2-6 years.

The proportion of dietary energy from fat showed a marked urban/rural differential, with urban women and children consuming $27.5 \%$ and $28.7 \%$, respectively, of dietary energy from fat while rural women and children consumed about 5\% less of dietary energy as fat. The highest fat intakes were predictably reported from Cairo, where the average intake was 30\% of dietary energy for women and $31 \%$ for children. Fat intake in Egypt is primarily from vegetable oil, which is utilised in the preparation of almost all mixed dishes, rice and fava beans; margarine in urban areas and ghee in rural areas make up most of the remainder of the fat intake. Dietary fibre intakes were generally quite high, averaging about $30 \mathrm{~g} \mathrm{day}^{-1}$ for women. Energy intakes for women were generally as predicted for individuals undertaking light activity levels ${ }^{12}$. Dietary quality was problematic for a large part of the population, with more than one-third of women and children failing to meet $50 \%$ of recommended intakes for calcium, vitamin A and available iron. Eleven per cent of households were classified as food-insecure (defined as reporting more than 75\% of cash income spent on food, as well as giving a food-related answer to an open-ended question about the projected uses of any hypothetical increase in household income), with a regional variation ranging from $4 \%$ in the Cairo governorate to $22 \%$ in Dahkhalia. Risk of poor dietary quality was significantly higher for both women and children in foodinsecure households, as was the risk of low energy intake for children.

The second round of this survey, in five governorates only one of which (New Valley) overlapped with the 1994 round, was undertaken in 1998-1999, and the results have not yet been formally reported, although anthropometric data from that survey are reported in the present paper.

\section{Anthropometric indicators of nutritional status}

Obesity among adults, particularly women, has reached very high proportions in Egypt in the last few years, while malnutrition rates in pre-school children remain stubbornly high. The 1998 national food consumption survey reported underweight in $16.7 \%$ of $2-6$-year-old children and $7.4 \%$ of $6-10$ year olds, but none in children and youth aged $10-18$ years. Overweight and obesity affected $1.6 \%$ of $2-6$ year olds, $4.9 \%$ of $6-10$ year olds, $14.7 \%$ of 10-14 year olds, and $13.4 \%$ of 14-18-year-old children. The prevalence of stunting in pre-school children ranged from 13\% in Lower Egypt to 24\% in Upper Egypt. These results give somewhat lower estimates for early childhood malnutrition than the 1995 Egypt Demographic and Health Survey that showed a stunting prevalence of $36.4 \%$ in Upper Egypt (39.7\% rural and $27.2 \%$ urban) and $28.0 \%$ in Lower Egypt (28.8\% rural and 25.6\% urban). The large 1994 food consumption monitoring survey also measured children, aged 2-6 years, and reported 31\% of children stunted and $11.2 \%$ underweight $^{11}$. Prevalences of wasting among pre-school children are consistently around 5\% in the various surveys (Table 2). 
Table 2 Prevalences of stunting, underweight and wasting (\%) among Egyptian pre-school children in various surveys

\begin{tabular}{|c|c|c|c|}
\hline Survey and age group & $\begin{array}{c}\text { Stunting } \\
\text { (height-for-age } \\
\leq-2 \text { Z-score) (\%) }\end{array}$ & $\begin{array}{c}\text { Underweight } \\
\text { (weight-for-age } \\
\leq-2 \text { Z-score) (\%) }\end{array}$ & $\begin{array}{c}\text { Wasting } \\
\text { (weight-for-height } \\
\leq-2 \text { Z-score) }(\%)\end{array}$ \\
\hline 1995 Demographic and Health & 36.4 (Upper Egypt) & 16.0 (Upper Egypt) & 5.2 (Upper Egypt) \\
\hline Survey (DHS) (6-60 months) & 28.0 (Lower Egypt) & 9.6 (Lower Egypt) & 3.0 (Lower Egypt) \\
\hline 1998 National Food Consumption & 13.0 (Lower Egypt) & 16.7 & \\
\hline Survey $(2-6$ years) & 24.0 (Upper Egypt) & & \\
\hline $\begin{array}{l}\text { Food Consumption Monitoring } \\
\text { Survey } 1994 \text { (2-6 years) }\end{array}$ & 31.3 & 16.4 & 5.7 \\
\hline
\end{tabular}

Some limited data have documented the emergence of obesity among urban teenagers ${ }^{13-15}$, but national data do not show significant prevalence in this age group. Anthropometric status of adolescents has recently been documented on a fairly large national sample of children, ages 10 to 19 years $^{12}$. While $17 \%$ of boys and $15 \%$ of girls were classified as stunted (with expected socio-economic and rural/urban differentials), overweight is much rarer. A comparison of body mass index (BMI) distribution indicates that Egyptian boys are somewhat thinner than the World Health Organization (WHO)/National Center for Health Statistics (NCHS) reference population at the 95th percentile, the median and the 5 th percentile. Egyptian girls have a somewhat heavier 50th percentile than the international reference across the age range, but similar 5th and 95th percentiles.

The largest sets of recently measured anthropometric data on adults come from the 1994 and 1998-99 food consumption monitoring surveys. Heights and weights of women were measured in both rounds; men were measured only in 1998-99. The two surveys did not sample the same governorates (with the exception of one small governorate, New Valley) but used identical measurement protocols and sampling schemes within governorates. There is an evident difference in average BMI for urban women between 1994 and 1998-99 (i.e. 27.7 and $30.0 \mathrm{~kg} \mathrm{~m}^{-2}$, respectively). In 1998-99, the average BMI for women was obese by international standards (Table 3). The prevalence of obesity, defined as $\mathrm{BMI} \geq 30 \mathrm{~kg} \mathrm{~m}^{-2}$, was $45 \%$ in urban women in 1998 and more than 20\% among rural women and in men (Table 4). About $5 \%$ of women were severely obese (BMI $\geq$ $40 \mathrm{~kg} \mathrm{~m}^{-2}$ ). The higher prevalence of obesity in women

Table 3 Body mass index (BMI) in Egyptian women, 1994 and 1998-99, and in men, 1998-99 (mean \pm standard deviation); Food Consumption Monitoring Survey data

\begin{tabular}{lcc}
\hline \multirow{2}{*}{ Sample } & \multicolumn{2}{c}{ BMI $\left(\mathrm{kg} \mathrm{m}^{-2}\right)$} \\
\cline { 2 - 3 } & Urban & Rural \\
\hline Women, 1994 $(n=5395)$ & $27.66 \pm 5.61$ & $29.51 \pm 5.86$ \\
Women, 1998-99 $(n=2909)$ & $30.08 \pm 5.51$ & $26.90 \pm 9.68$ \\
Men, 1998-99 $(n=1974)$ & $26.72 \pm 4.26$ & $24.28 \pm 3.47$ \\
\hline
\end{tabular}

than men is common almost everywhere and probably arises from a number of complex factors. Whether this difference is exaggerated, in populations in which childhood malnutrition is common, is a matter for debate. However, earlier documentation showed a delayed onset of puberty (by 1.2 years) and an extended period of pubertal growth in Egyptian boys ${ }^{16}$; it is not unreasonable to expect that this extended growth period provides some protection against short adult stature and later obesity risk.

A number of smaller-scale studies have documented similar high rates of obesity in adult women, and when socio-economic relationships were investigated they found that either (1) women of lower socio-economic status (SES) have higher rates of obesity than those of higher $\mathrm{SES}^{17}$ or (2) the prevalence of obesity is lowest at both the highest and lowest ends of the socio-economic spectrum $^{10}$. Any relationships between SES and obesity in Egyptian men are not apparent. Urban residence is clearly related to obesity risk ${ }^{11,18}$. There is a general dearth of physical activity estimates for the Egyptian population. A study of diabetes prevalence conducted in the early $1990 s^{18}$ incorporated an estimate of physical activity in a questionnaire (methods not further specified). The study results determined that $52 \%$ of rural adults, $73 \%$ of urban adults with lower SES and 89\% of urban adults of high SES led sedentary lifestyles; these rates paralleled the rates of obesity (16\%, 37\% and 49\%, respectively) and diabetes (4.9\%, 13.5\% and 20\%, respectively) in the sample.

\section{Obesity-related morbidity}

The health and nutrition transition in Egypt has been evident for some years; thus, there has been some impetus to collect contemporary data on chronic disease prevalence and trends. Data on hypertension and diabetes have been collected fairly recently on national samples of adults. Cardiovascular disease has risen steadily as a proportionate cause of mortality for both men and women, from $5 \%$ of deaths to $39.1 \%$ for men and from $2.9 \%$ to $27.2 \%$ of deaths for women from 1961 to 1985 , respectively ${ }^{19}$.

A recent large-scale survey designed to produce estimates of prevalence of high blood pressure indicates that Egypt has one of the highest rates in the world, 
Table 4 Prevalence of overweight $\left(\mathrm{BMI}=25-29.99 \mathrm{~kg} \mathrm{~m}^{-2}\right)$, obesity $\left(\mathrm{BMI}=30-39.99 \mathrm{~kg} \mathrm{~m}^{-2}\right)$ and severe obesity (BMI $\geq 40 \mathrm{~kg} \mathrm{~m}^{-2}$ ) for women, 1994 and 1998-99, and prevalence of overweight and obesity (BMI $\geq$ $30 \mathrm{~kg} \mathrm{~m}^{-2}$ ) for men, 1998-99, by rural/urban residence; Food Consumption Monitoring Survey data

\begin{tabular}{|c|c|c|c|c|c|c|}
\hline \multirow[b]{3}{*}{ Sample } & \multicolumn{6}{|c|}{ Prevalence (\%) } \\
\hline & \multicolumn{3}{|c|}{ Urban } & \multicolumn{3}{|c|}{ Rural } \\
\hline & Overweight & Obesity & $\begin{array}{l}\text { Severe } \\
\text { obesity }\end{array}$ & Overweight & Obesity & $\begin{array}{l}\text { Severe } \\
\text { obesity }\end{array}$ \\
\hline Women, $1994(n=5395)$ & 36.3 & 36.7 & 5.0 & 38.7 & 24.1 & 3.5 \\
\hline Women, 1998-99 $(n=2909)$ & 39.6 & 40.6 & 4.6 & 36.5 & 19.4 & 1.4 \\
\hline Men, $1998-99(n=1974)$ & 45.3 & 20.0 & & 28.1 & 6.0 & \\
\hline
\end{tabular}

according to its authors ${ }^{20}$. The National Hypertension Project, conducted between 1991 and 1994 by a joint Egyptian/US team, collected data on more than 3000 adults, 25 years and older, from 21 sampling units in six governorates. Blood pressure was measured four times with standardised protocols. Hypertension (defined as systolic pressure $>140 \mathrm{mmHg}$, or diastolic pressure $>90 \mathrm{mmHg}$, or currently taking anti-hypertensive medication) prevalence was $26.3 \%$, steeply related to age up to age 65-74 years and highest in Greater Cairo. Awareness, treatment and control percentages were generally relatively low $(37.5 \%, 23.9 \%$ and $8 \%$, respectively). Men were more likely to be hypertensive until age 45 , after which women had higher rates than men. Salt intake, indexed by 12-hour urinary sodium excretion, was correlated positively with risk of hypertension with the highest levels in occurring in Cairo governorate. Obesity $\left(\mathrm{BMI}>30 \mathrm{~kg} \mathrm{~m}^{-2}\right.$ ) was more common in hypertensive subjects $(39.8 \%)$ than in normotensive subjects (26.5\%).

Two recent surveys have attempted to document the prevalence of diabetes mellitus among Egyptian adults. The first was a population-based survey of persons $\geq 20$ years of age in Cairo and surrounding rural villages conducted by the Egyptian Ministry of Health and the US Centers for Disease Control and Prevention ${ }^{18}$. More than 4000 individuals had capillary blood glucose measured. Sampled neighbourhoods were selected to represent rural, urban low socio-economic status, and urban high socio-economic status. The prevalence of diabetes, defined by the WHO criteria (postprandial blood glucose $>200 \mathrm{mg} \mathrm{dl}^{-1}$ ) was $4 \%, 13.5 \%$ and $20 \%$ in rural, low-SES urban and high-SES urban areas, respectively. Expanding the estimates of diabetes and the risk factors of obesity and sedentary lifestyle to the Egyptian population generally, the authors estimated that $63 \%$ of the Egyptian population, 20 years and older, is sedentary and $27 \%$ is obese, with $5.4 \%$ having diagnosed diabetes and 4.0\% with undiagnosed diabetes. A direct relationship between diabetes and obesity was evident, with rates of obesity and diabetes being $16 \%$ and $4.9 \%$ in the rural sample, $37 \%$ and $13.5 \%$ among low-SES urban subjects and 49\% and 20\% among higher-SES urban residents, respectively. The second survey $^{21}$ studied almost 5000 individuals $>10$ years of age
(2920 over age 30 years) in 11 governorates selected to represent urban (Alexandria, Damanhour and El-Mahala), rural agricultural Nile Delta areas and rural desert groups. The same criteria, namely those elaborated by WHO, were used to define diabetes. Rural prevalence rates duplicated the estimate of $4.76 \%$ from the Cairo study. Urban prevalence estimates were somewhat lower than the Cairo study, at $11.85 \%$ in individuals $>30$ years of age. The lower estimate for urban adults, from that of the Cairo study, may be attributable to the environment of Cairo vs. other cities. However, it is more likely due to the sampling procedure for the Cairo study, which used a two-stage sampling procedure designed to emphasise persons at high risk for diabetes based on a casual capillary blood glucose value. The overall population estimate of diabetes for individuals $>10$ years of age in the wider study was $4.58 \%$.

Trends in cancer rates will be of great interest in terms of the Egyptian nutrition transition, since the obesity rates among women are so high. However, the country lacks a population-based tumour registry. The best available data on cancer sites in the Egyptian population come from two large clinical pathology series, one from the National Cancer Institute and the other from a large private oncology clinic, and have recently been reviewed ${ }^{22}$. Breast cancer is the most common type (24.3\%), followed by cancer of the urinary bladder (18.2\%), the gastrointestinal tract (18.4\%) and lymphoma (9.8\%). The high incidence of bladder cancer is secondary to chronic schistosomiasis. Other cancers common in developing countries (liver, uterine, cervix) and diet-related cancers, other than breast cancer (colorectal and prostate), are relatively low.

Other obesity-related morbidity has been little studied, but we investigated functional correlates of adult obesity in a village population in the mid-1980s ${ }^{23}$ and found higher rates of diagnosed diabetes and heart diseases, as well as a higher prevalence of respiratory ailments, in obese women compared with non-obese women.

\section{Summary and conclusions}

The nutrition transition in Egypt has occurred in the context of abundant dietary energy availability, urbanisation and moderate fat intakes on average $(22 \%$ 
of dietary energy in rural areas and $27 \%$ in urban). The prevalence of obesity in adults is very high, particularly among women. The prevalences of diabetes mellitus and of hypertension parallel that of obesity, and both are very high. Little information is available on physical activity, but it is likely that a large proportion of the population is quite sedentary, particularly in the cities. At the same time, rates of early childhood malnutrition remain stubbornly stable and relatively high. The 'double burden' of obesity and malnutrition is clearly evident. Public awareness of the increasing prevalence of obesity and of diet-related chronic disease is increasing, and attention has turned to documenting the problem(s). Today, policy-level awareness in the health sector is disease-specific with little attention to unified underlying causes. However, there is growing recognition in the agricultural and education sectors of the necessity for better nutrition 'awareness' and guidance toward healthful dietary choices and physical activity in the population. The fact that greatly increased food production over several decades has not eliminated malnutrition has turned attention to the general influence of diet on the health of the population, and there is some progress, in the very recent past, to a comprehensive approach to dietary guidance and health promotion.

The question arises as to the reasons behind the extraordinarily high prevalence of obesity among Egyptian women. Although overweight and obesity are apparently still increasing in prevalence, the phenomenon has been evident for at least 20 years. The 1981 national food consumption survey ${ }^{8}$ included measurements of the mothers and fathers of sampled children and reported $63.1 \%$ of mothers and $14.5 \%$ of fathers to be overweight or obese (i.e. $>110 \%$ of the standard weight) at that time. The combination of urban living and an abundant food supply does not, by itself, provide the entire explanation. It is very likely that the cultural preference for female plumpness (only recently beginning to change ${ }^{24,25}$ ) coupled with physical and cultural barriers to physical activity make the difference. For example, the recent predominance of apartment buildings higher than six floors (the threshold requiring the installation of elevators) means that fewer families live in buildings requiring or even permitting stair climbing. Organised 'sporting clubs' are confined to the higher socio-economic classes, and in any case seldom encourage much activity on the part of women; there is a lack of physical education in schools; and there is an absence of women's participation in sports in general. Similar cultural barriers to physical activity have been noted in relation to the very high prevalences of obesity among adult women in Saudi Arabia ${ }^{26}$. An active lifestyle for both men and women can easily be promoted in Egypt, particularly in the context of its health benefits, but so far there has been little attention to this particular problem.

\section{Acknowledgements}

The author is grateful to Drs Ezzat Khamis, Fikrat El-Sahn and Emad Salama for providing original documents, to Ame Stormer for technical assistance and to Dr Gail Harrison for editing the manuscript and for substantive input.

\section{References}

1 El Zanaly F, Sayed HAA, Zaky H, Way A. Egypt Demographic and Health Survey 1996. Calverton, MD: National Population Council, Arab Republic of Egypt and Macro International, 1996.

2 Ministry of Supply and Home Trade. The Egyptian Food Problem and Solution. Cairo: Ministry of Supply and Home Trade, February 1988.

3 York ET, Pluchnett D, Yougbos H. The National Agricultural Research Project's Contribution to Significant Advances in Egyptian Agriculture. Gainesville, FL: Tropical Research and Development, Inc., 1994.

4 Ministry of Agriculture, Agricultural Economics Research Institute (Cairo). Agricultural Economics Bulletin 1983; 10.

5 Harik I. Subsidization policies in Egypt: neither economic growth nor distribution. Int. J. Middle East Studies 1992; 24: 481-99.

6 Ministry of Health. Report of the Permanent Nutrition Committee (PNC), Egypt, 1939-1946. Cairo: Ministry of Health, 1948.

7 Abdou IA, Amr MAK. Nutritional conditions in Sinai': I. Available foods, food habits and daily dietary intake of different population groups in Sinai'. Bull. Nutr. Inst. (Cairo) 1966; 2: 10-25.

8 Patwardhan VN, Darby WJ. In: Darby WJ, ed. The State of Nutrition in the Arab Middle East. Nashville TN: Vanderbilt University Press, 1972.

9 Nutrition Institute. Studies of Food Consumption Patterns of the Egyptian Citizen. Cairo: Nutrition Institute, 1981.

10 Nutrition Institute. Food Consumption Pattern and Nutrient Intake among Different Population Groups in Egypt. Cairo: Nutrition Institute, 1998.

11 Khorshid A, Ibrahim N, Galal O, Harrison G. Development of food consumption monitoring system in Egypt. $A d v$. Agric. Res. Egypt 1998; 1(3): 163-217.

12 Harrison GG, Galal O, Ibrahim N, Stormer A, Khorshid A, Leslie J. Lack of underreporting of food intake in a large sample of Egyptian women. J. Nutr. 2000; 130: 2049-54.

13 Ibrahim B, Sallam S, El Tawila S, Gibali O, El Sahn F. Transitions to Adulthood: A National Survey of Egyptian Adolescents, 2nd ed. Cairo: The Palm Press, 2000.

14 El-Zeiny NA, Mostafa SRA, Moamen MH. Study of obesity among secondary students in Alexandria. Alexandria $J$ Pediatr. 1999; 13(2): 397-406.

15 Ismail GMN. Study of obesity among school students in Alexandria. Unpublished DrPH thesis, Alexandria University, High Institute of Public Health, 1996.

16 Hafez AS, Salem SI, Cole TS, Galal OM, Masoud A. Sexual maturation and growth pattern in Egyptian boys. Ann. Hum. Biol. 1981; 8: 461-8.

17 El-Prince MY. A study of prevalence and etiological factors of obesity among adults in Alexandria. Unpublished MPH thesis, Alexandria University, High Institute of Public Health, 1987.

18 Herman WA, Ali MA, Aubert RE, Engelgau MM, Kenny SJ, Gunter EW, et al. Diabetes mellitus in Egypt: risk factors and prevalence. Diabet. Med. 1995; 12: 1126-31.

19 World Health Organization, Eastern Mediterranean Region Office, Alexandria, 1999

20 Ibrahim MM. Epidemiology of hypertension in Egypt. Saudi J. Kidney Dis. Transplant. 1999; 10(3): 352-6. 
21 Arab M. Epidemiology of diabetes mellitus in Egypt. Egyptian J. Diabet. 1997; 2(1): 1-14.

22 El Hattab OH, Nouh MA. Epidemiology of cancer. In: El Bolkainy MN, ed. Topographic Pathology of Cancer. Cairo: National Cancer Institute, 2000

23 Khan LK, Harrison GG, Galal OM, Ritenbaugh C, Shaheen FM, Kirksey A, Jerome NW. Prevalence and functional correlates of obesity in an Egyptian Village. Ecol. Food Nutr. 1996; 34: 311-25.
24 Galal OM. Paper presented at the Middle East Studies Association, San Francisco, CA, November 1997

25 Basyouny IF. Just a Gaze: Female Clientele of Diet Clinics in Cairo: An Ethnomedical Study. Cairo: American University Press, 1998.

26 Al-Nuaim AA, Bamgboye EJ, Al-Rubeaan KA, Al-Mazrou Y. Overweight and obesity in Saudi Arabian adult population: role of sociodemographic factors. J. Community Health 1997; 22: 211-23. 